\title{
Research on the Promotion of CCP to Conventional Industries- Taking Rizhao Green Tea as an Example
}

\author{
Yu-chen LIU, Zhu LIU \\ Rongcheng College of HUST, Rongcheng, Shandong, China
}

Keywords: Rizhao Green Tea; CCP; Packaging Design; Conventional Industries.

\begin{abstract}
As a representative industry in the new stage of economic development, China's modern CCP can increase added value and further upgrading and development of conventional industries after its integration with them. Rizhao Green Tea is lack of related products with poor exploitation consciousness. Its cultural value, technological value, tourism value, recreational value and health value fail to develop well. Without being recognized in the market, the CCP extended from green tea cannot reflect its unique advantages with the identical and rough packaging design. China's conventional packaging design principles should take ethos as the root, natural law as the theory, innovation and development as the goal, conducting in-depth reform and development in modern packaging design on the basis of inheriting and drawing lesson from traditional culture to enrich cultural deposits and enhance cultural value of the commodities. The expansion of the CCI has become a new engine in tourism.
\end{abstract}

\section{Introduction}

Today, the development prospect of CCI is considerable with our national economy growing by leaps and bounds. For the design and packaging of our modern CCI, it is a key that whether it can show Chinese characteristics and regional style by a successful breakthrough in external performance and then upgrade to the cultural connotation. People are very glad when paying for the perfect combination of culture and commerce. Through exploring cultural tourism souvenirs, office supplies, agricultural and sideline products, and handicrafts and other inherent cultural connotations, they enhance its commercial value. Packaging design of products is an important form of cultural tourism, which is why as mass consumer product, tea packaging design that acts as a substantial carrier of tea culture should also meet people's physiological and psychological needs. As for Rizhao Green Tea packaging design, we need to start from its own regional features and historical and cultural point of view to forge its unique brand image. Through developing CCI, we can promote the development of local conventional industries, strengthen the construction of urban infrastructure, create employment opportunities, enhance the cultural taste of the city, develop characteristic tourism and so on.

\section{The Development of CCP}

$\mathrm{CCP}$, namely cultural and creative product, is an emerging industry with creativity as the core under the background of economic globalization. It emphasizes that a main culture or cultural factor depends on individual (team) through technology, creativity and industrialization to develop and market products that extended from intellectual property rights. Its core is spiritual product, which determines that the CCI has the characteristic of innovation and culture, as well as high permeability, externality, high added value etc.. Therefore, China's modern CCI is a typical industry in the new economic development stage, and it can improve the added value and promote the upgrading and development of the conventional industry after their integration. It is of great significance to the adjustment and transformation of the entire economic structure and the economic growth rate. The research and development process of CCP is to extract the shape, material, technology, cultural symbols and spiritual connotation of the original carrier, and through abstract processing, then translated into products with modern aesthetic, cultural language and practical functions. China's CCP needs nationalism which derives from our traditional culture. Mr. Lu Xun 
said, "The more nationalism and locality of works, the more cosmopolitan." For example, the sales of CCPs was over one billion during 2017 in the Palace Museum in Beijing (Fig.2) the British Museum's Tianmao flagship store had more than 130,000 fans in less than a month's online time and most of the products were snatched up (Fig.2). From these, we can see there's a huge development space for CCP. Tea, which has a history of over 3,000 years, is a great treasure of our country and an agricultural product with Chinese characteristics. In recent years, China's tea consumption is in a transitional period, and the tea industry is the well-deserved sunrise industry. According to the survey, nearly 50\% Chinese people are in the habit of drinking tea. Tea culture is born with the emergence of commodity economy and the formation of urban culture. Tea peripheral product packaging also needs to be combined with its rich cultural and historical background and CCP - that is to say relying on historical deposits and today's creation - to realize the transformation from folk to urban, from tradition to modern.

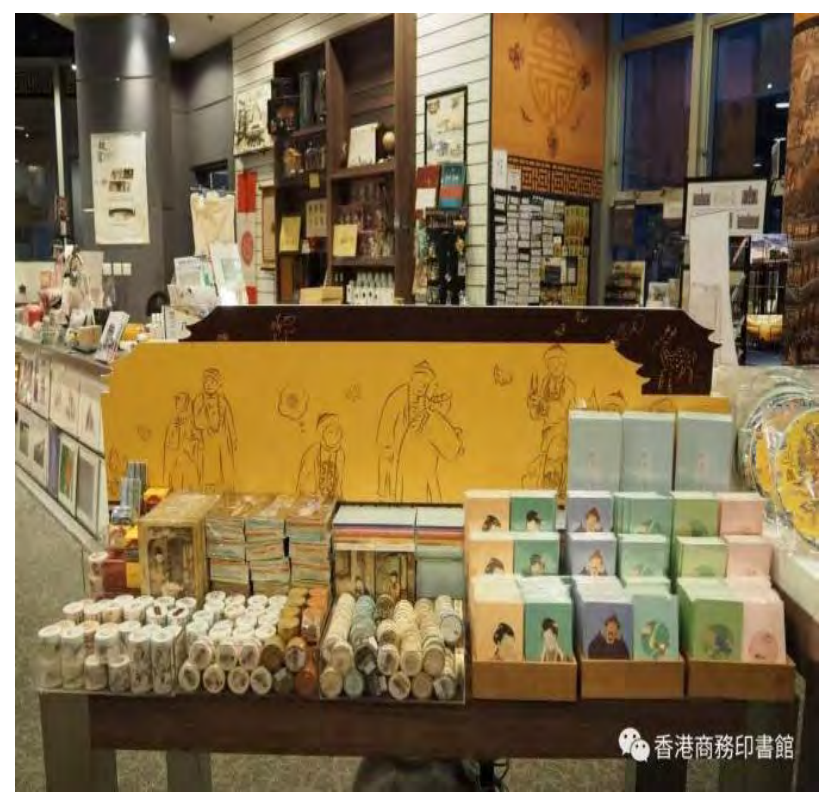

Figure 1. CCPs in Beijing Palace Museum
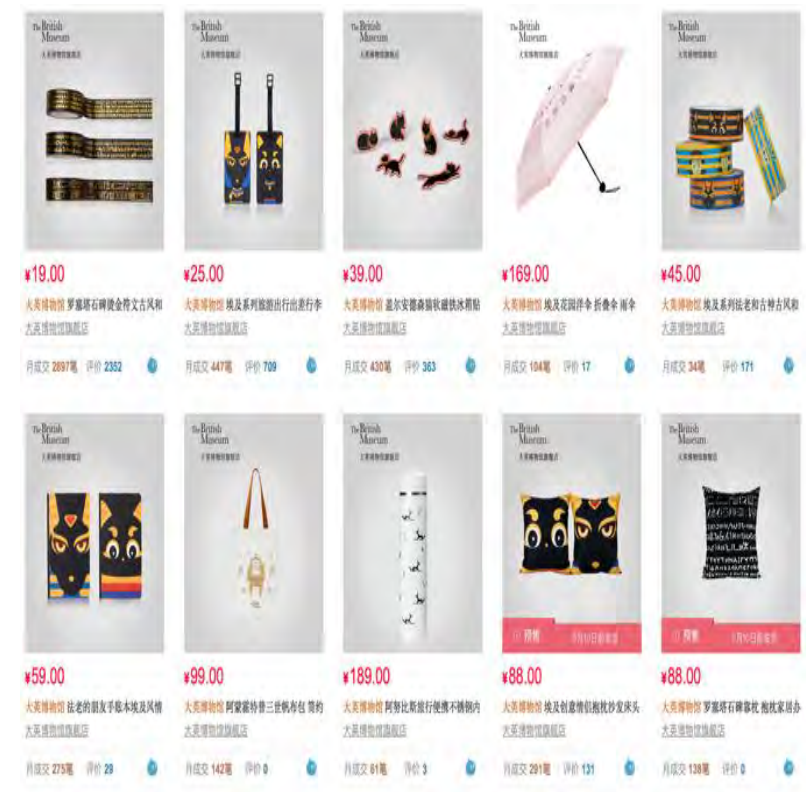

Figure 2. On-line Sales in British Museum

During the 5,000 year's history of Chinese civilization, tea culture almost went together all the way with China, the big country of traditional tea drinking. Lu Yu's Tea Classics records: "using tea as a drink started at a man named Shennong, and it has been popular since the Duke of Lu Zhou era." Shennong was the first man to drink tea in our country, and tea drinking had been widely circulated when the Duke of Lu Zhou in Shandong began. There were reports of tea production in Shandong Province since Ming Dynasty. In the last century, the introduction of tea from the south to the north was the restoration of tea industry in this province. With the successful planting of "South-to-North" tea, green tea has been rapidly popularized in Shandong Peninsula, Southeast and Central-South Shandong, and three strains of Laoshan Green Tea, Rizhao Green Tea and Yimeng Green Tea have been gradually formed.

As a populous province, Shandong Province has a huge tea consumer group while the annual output of tea is only about 20,000 tons. The "seller's market" in short supply makes it the province with the highest price of tea in China. Meanwhile, as a direct port the south of Shandong Province, Rizhao is adjacent to Qingdao and Lianyungang, and across the sea from Japan and South Korea. Its west links many inland provinces of China. Besides, railways can reach European ports such as Rotterdam and Antwerp. It also plays a role of the eastern bridgehead of the New Asia-Europe Continental Bridge. The superior geographical position has created favorable conditions for the logistics of Rizhao Green Tea.

Rizhao City is the largest green tea production base in Shandong Province and one of the three coastal green tea cities recognized by tea scientist all over the world. Compared with the traditional tea producing areas in South China, it has more obvious geographical advantages, such as long 
growth cycle, large temperature difference between day and night, which is conductive to the accumulation of inclusions, rich in vitamins and minerals, as well as useful trace elements to human body. Not only the selenium content of Rizhao Green Tea is 6.1 times that of South China tea, it also has a special role in radiation protection. According to scientific statistics, its contents of tea polyphenols and other nutrients in are much higher than those in other green tea. Rizhao Green Tea's geographical and environmental factors contributed to its thick buds and leaves and stout appearance. However, it is dark green and solid as a rough man of Shandong Province. Also, like the shape of sturdy pine, it remains stalk style after brewing. There is no morbidezza and beauty of southern green tea at all. The liquor of the brewed tea is clear and bright in color with chestnut fragrance and mellow aftertaste. After the first brewing, the tea leaves still maintain slightly tight, which can beboiled and drunk many times. The characters of Rizhao Green Tea and people live in Shandong Province come down in one continuous line, which means the former is the epitome of the latter.

Although the reputation of Rizhao Green Tea is tolerable in Shandong Province, its publicity is weak nationwide. Because of its late entry into the market and low popularity of the city, it survives in the crack between "Laoshan Wanlijiangshan Tea" and "Yimeng Chunshanxueya". The reason is that Rizhao Green Tea is lack of related products with poor derivatives exploitation consciousness.

Therefore, its cultural value, technological value, tourism value, recreational value and health value etc. have not been well developed. Without being recognized in the market, the CCP extended from green tea can not reflect its unique advantages.

\section{Designing of Green Tea Package}

With a combination of several subjects, package design is an art layout for business use, including that visual communication language, such as design, structure, pattern, color and font, that factors of technique and quality, and that the knowledge of aesthetics, consuming psychology, brand marketing, marketing, modern storage and transportation, consumer behavior. As an art, physical appearance of goods, the package, is a way to speak of the needs of modern citizens in accordance with their material lives and spiritual lives. Package of tea is specially designed with spirit of tea, which leads to a more specific appearance than traditional industrial products. Nowadays consumers are not only paying for the pure material value of tea any more, but the cultural experience coming along with it, from which we could draw a conclusion that the package of tea may affect the consumption attitudes. This specially designed package is increasing the culture value of tea while bringing the spirit of Chinese tea to the whole world. We can only tell the quality from actually tasting the tea, a unique product, so that we recognize the brand of a tea company through package patterns. Perfect package attracts attentions while helping tea companies to win the trust of consumers and accelerate the process of taking a bigger market share.

With the combination of same moulds and simple patterns, Chinese green tea packages are generally designed in a general way. Basically those almost same packages lead to the patterning of traditional decorations which are put together without originality instead of serving the artistic conception of overall packing. Many companies is losing their brand effect since the shortage of brand awareness and the lack of advertisement of regional culture and folk culture, so that the products of those companies come to common and formalization. What's more, the quantities of packaging waste had a sharp rise and much material out into packing producing was in vain, and all above was on account of over-packaging of tea to attract consumers in recent years. Now there is tea of high quality in the market just as the tea of bad quality and package then fails to help the consumers to tell the bad tea from perfect tea.

To face the reality, the traditional package design will have to be improved in accordance of our ethos and natural laws with a target of developing our tea package with innovation. We must go further in the improvement and development of modern package based on traditional culture so as to increase the culture deposits and value behind the products. A company of green tea package business pays attention not only on the material of outer part but also on the combination of color and pattern on the package, plus the advertisement of the brand. 


\subsection{Materials}

Modern package designing comes to the principle of environmental protection after 21 century and the principle is increasingly accepted by all countries in the world. Now biodegradable material and pollution-free ink are both the perfect choice in the process of production. More attention was transferred from practicability and rationality to the harmony between man and nature while designing the package. To take the best advantage of the natural materials, we have to produce more effectively. One of the most wonderful materials used for tea package is biodegradable paper that is cheap and easy to recycle. Recycled paper is good for environment and the conservation of energy and resources as materials of tea package. So a traditional package of kraft without smell from Shandong province has to mentioned because of its' unique qualities of dampproof, anti-oxidation, opacity and gas barrier property. What's more, this Shandong kraft is also anti-extrusion during transportation. Company can also choose bamboo as package materials from the famous oxygen bar of bamboo grave in Rizhao city. To keep the tea fresh in container, bamboo is a good choice for its' blocking property, opacity and closure. According to the principle of green packaging and resources recycling, consumers can make home decorations, pen container or cabinet, out of the cheap tea package whose materials were obtained locally.

\subsection{Color Scheme and Decorative Figure}

In consumer's mind, the process of recognizing package of products started from perception and end in thought. In accordance with product attributes and cognitive psychological process of potential consumers, a designer should provide them with perceptual elements of mind on tea package by the combination of color, the arrangement of pictures and word, the artistic structure and the quality of products. In this way wonderful imagination and satisfying consumer psychology will be rising up and intense desire to buy will come into being. Traditional decorating symbols used on the package designing should go along with the contents of products and the idea of modern packaging, so that a company can emphasize the feature of traditional culture of tea product and also the spirit of modern art of designing. While keeping the lasting nature of culture, more attention should be applied to development which requires to safeguard tradition and improve innovation, the contrary between public commonality and localism, modern techniques and traditional culture should be dealt with. A tea company may take advantage of three basic elements of tea, bamboo and pottery in Rizhao city. Sitting in a bamboo grave, one may notice the beautiful shadow of bamboo and the gentle smell of tea from pottery feeling like living in the heaven with sunglow rising up. Thoroughly enjoying yourself with tea and endless small talk, we can see a poetic world with main tone of blue and green of low saturation from which one can tell the moral of it that blue see under clear sky surrounds the grave the tea and green bamboo.

The color of blue is often associated with wisdom and immortal in China, while green is a symbol of energy and simplicity. Staring at green creature can also keep the blue away and motivates people. Unique and energetic handwriting of tradition is chosen for words on the package.
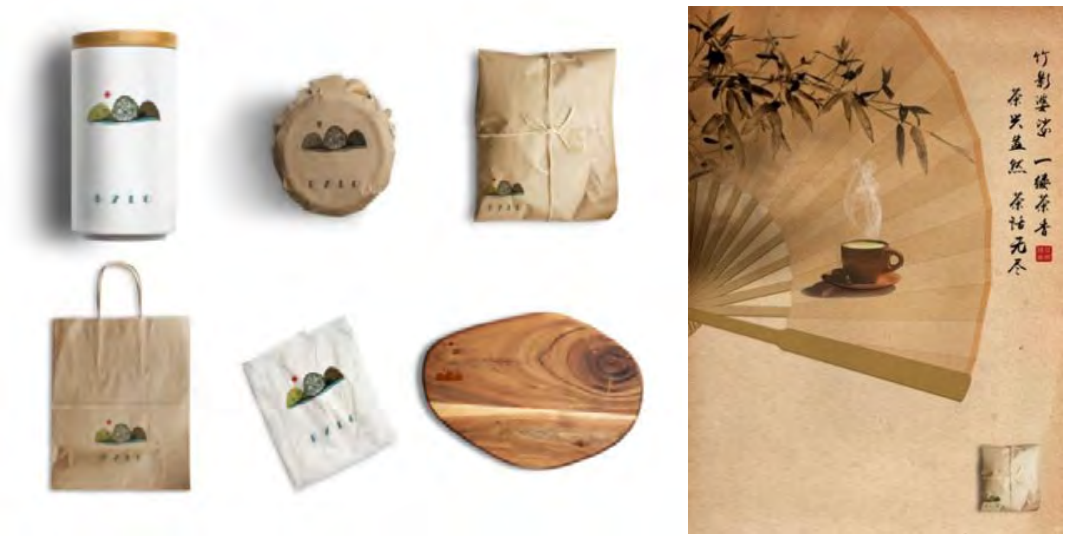

Figure 3. Packaging Designs of Rizhao Green Tea 
Consumers can experience the beauty of the art of traditional handwriting through copious and fluent Xingshu with freestyle and the nature of Rizhao green tea to seek for freedom (Fig.3). Perfect products with culture innovation must be designed after thorough study of culture deposits, and they are paid for by consumers for their physical needs of material, self-improvement and spiritual life.

\subsection{Brand Building}

All brands make remind people of special characteristics and images they boost of. The brand with high associations will leave the first impression on consumers who attach it great importance subconsciously. Later, the brand will play a leading role. With the advancement of market economy and the changes of effects of consumers' mindsets, packaging design of tea gradually is now catering to various consumers to meet their psychological needs and market demand. Consumers purchase products to express themselves genuinely. Therefore, brands need to first, reach out to the mental mind of consumers, before they can establish with a close tie with consumers and arouse their purchasing desire. Devising different ways of packaging cases aimed to different consumers is beneficial to defining or strengthening the self-image of a brand. The consumable patterns of drinking in China, most consumers of tea in bulk are middle-aged while beverages and coffee are more popular among young people, which requires packaging design to take proper strategies to meet different consumers' needs to the greatest extent. For the middle-aged with rich social and life experiences, they highly value development-centric consumption, especially the educational development for themselves or for their children and emphasis the grade of products as well as brand equality. Accordingly, they are willing to buy medium-high grade teas. The consumption desire towards the elderly prefers their unchangeable habits. They incline to stay with familiar interests, particularly traditional interests that are not easily affected by society and surroundings. Thus, the right approach is to take popular tea packaging that adapts to the changes of physiological conditions of the elderly, which are also involved in leisure consumption tradition. But as for children and teenagers with great curiosity, they are sensible about what are new and tend to learn what they never learned, so there is a quite complex negotiation process between their parents and themselves. That requires the packaging design not only to please children, but to assure parents as well. Meanwhile, combining with factors of regional culture with modern products and taking use of visible products to explain the meaning of invisible factors of regional culture are available for consumers to realize the characteristic of regional culture and permeate down to users from actions to minds, and further to spirits step by step, causing in them a strong resonance.

\section{The Development Conception of Cultural and Creative Industrial Park}

At the beginning of 21 th century, realizing the enormous commercial space hid behind cultural tourism, China gradually started laying emphasis on the development of cultural and creative industries, which have become a new engine of tourism development in the extension of tourism fields. Tea culture tourism, titled with tea and its culture, is a series of tourism activities with various forms and rich contents, allowing consumers to rest, to play and to acquire knowledge about tea. Currently, the advancement of green tea produced in Rizhao city, Shandong province, has wonderful opportunities and bases: warmer temperature in northern coastal tourism vitalizes the development of tea industries and furthermore, significant natural characteristics appear in rural developing areas, a bright spot formed with combinations of industries in the area. The mode of original ecology is exactly the ideal way which modern people pursue health and tastes for life. Out of question, it provides good basic environment conditions for green development of green tea in Rizhao. In the development of its green tea, natives must firmly seize, protect and make full use of the unique vantage and the opportunity, promoting applications of green resources

\subsection{Museum of Green Tea}

Museum of green tea, a place to collect, display and narrate the material heritage of tea culture, offers learning, education and entertainment equipment to the public. It also shows the culture and historical origins of Rizhao green tea. Narrations of products cease to be the design limited by a 
point; rather they take cultural value system into account. Additionally, the museum takes the real bamboos to the exhibition halls, creating an organic integration between tea culture and the environment. It also includes a VR experience area so that narrative characteristics of products can be enhanced using VR virtual reality technology. By the combination of light perception, sensing, and vibration, it can simulate real situation to create a fully immersed experience. High-tech means make it easier for visitors to fully understand the cultural aspects of tea.

\subsection{The Museum of Cultural Experience}

The museum of cultural experience is divided into three parts: green tea-growing areas, hand-making tea processing areas, and the exhibition hall of tea art. Visitors will have the personal experiences of collecting tea in spring, summer, and winter and closely contacting with the nature in action. Currently, with the guidance of tea frying workers, you will feel the elegance of traditional fried tea and real experiences of traditional hand-making of temperature and emotion when tea-making machinery is prevailing. In the well-proportioned tea garden, you will appreciate tea art performances of green tea, taste the Rizhao green tea which is "boiled the tea in a seemingly like teapot until it grows yellow, and later skims the surface foam of it", and enjoy special snacks made by tea as well as the spiritual connotation of tea culture.

\subsection{Special Residential Areas}

The residential area is an essential holiday product. It should blend with local folk characteristics and improve the surrounding infrastructure construction of tea producing areas. Major tea cultivation areas include Jufeng town, Lanshan district, Rizhao city and its surrounding areas. In terms of cultivation areas, Rizhao can create a residential region of beautiful tea villages, where countryside is the dependence and the core is tea industry. Relying on a natural tea village, planting basis in tea industries are wide; therefore, villagers will not have to move away but to be rich by devoting themselves to tea tourism service industry. Resorting to its own development advantages, Rizhao has built a novel image of cultural brand and has followed a road of times development which is new, internationalized with local features. And it has given an edge for the tea brand of Rizhao green tea to stand out from all kinds of famous teas on the highly competitive market.

\section{Summary}

Learning cultural and creative products of Rizhao green tea can step up its influence and popularize special tea culture tourism. We should, therefore, optimize the development of traditional industries to integrate ecological sightseeing, experiences of tea culture, tea trade combined with rural leisure. Creative design in cultural and creative industries has closely combination with industry, agriculture, and the service industry. As a new industry bred in the era of rapid economic and cultural development, the cultural industry is becoming more deeply blended with other industries. The creative and cultural industry harbors great economic and social benefits. Organically combined with economy, culture, technology, and art, it will not only cultivate new points of economic growth, but drive industry upgrading, the advancement of modern service industry, the optimized development and transformation in urban areas, playing an important role in the promotion of cultural connotation in traditional industries and its internal quality.

\section{References}

[1] Hao Ninghui, The design principles and methods of creative and cultural products [M]. Beijing: Chinese Business Press, 2016.

[2] Liu Lin, Wang Kaili, Tan Haihu, ect., Research and application status of green packaging materials in China [A]. Packaging Engineering, 2016.

[3] Wang Shuliang, Zhang Yuhua, Chinese Crafts Arts History [M]. Chongqing University Press, 2010. 
[4] Ou Xiaojun, Jiang Limao, Xu Hanqiu, ect. Sichuan Province Agriculture and Agricultural Mechanization [J], 2016.

[5] Ji Xing, The influence of consumer psychology on contemporary packaging design [D]. Hebei University of Science and Technology, 2010.

[6] Zhang Yiwen, Chen Taiming, Sun Qiang, Development strategy of tea industry in Rizhao based on SWOT analysis [A]. Shandong Agricultural Sciences, 2010. 